\title{
Measures to Improve Robustness of Primary Containment Vessel and Operation of Filtered Containment Venting System Based on the Lessons from the Containment Leak at Fukushima Dai-ichi Nuclear Power Station Unit 2
}

\author{
Shinichi KAWAMURA ${ }^{1, *}$, Suguru OOKI ${ }^{2}$ and Tadashi NARABAYASHI ${ }^{3}$ \\ ${ }^{1}$ Nuclear Asset Management Department, Tokyo Electric Power Company, 1-1-3 Uchisaiwai-cho, Chiyoda-ku, \\ Tokyo 100-8560, Japan \\ ${ }^{2} R \& D$ Department, TEPCO Research Institute, Tokyo Electric Power Company, 4-1 Egasaki-cho, Tsurumi-ku, \\ Yokohama 230-8510, Japan \\ ${ }^{3}$ Division of Energy and Environmental Systems, Graduate School of Engineering, Hokkaido University, Kita-13, Nishi-8, Kita-ku, \\ Sapporo 060-8628, Japan
}

\begin{abstract}
Significant leakage of the primary containment vessel (PCV) occurred on March 15, 2011 at Unit 2 of the Fukushima Dai-ichi Nuclear Power Station, causing land contamination over a large area. From the radiation dose rate map of Unit 2 and the temperature trend of the PCV, degradation of the PCV top head flange gasket was identified as the cause of the leakage. The design set point of the rapture disc and operability of the valves in the hardened containment venting system were further identified as factors contributing to the leakage. Based on the lessons from the leakage, the gasket material was improved to have greater heat resistance in a steam environment, the PCV cooling system was diversified to improve reliability, and the operability and operation methods of the PCV venting were improved for greater robustness of the PCV in severe accidents.
\end{abstract}

KEYWORDS: accident, analysis, accident management, nuclear reactor, primary containment vessel, filtered containment venting system, gasket, Fukushima Dai-ichi, The Great East Japan Earthquake

\section{Introduction}

During the accident that occurred at Fukushima Dai-ichi Nuclear Power Station (hereinafter referred to as "Fukushima Dai-ichi") on March 11, 2011, a large amount of radioactive material was released into the air with serious consequences on the surrounding environment. Based on the investigation and analysis conducted thus far, which compared the results of monitoring

\footnotetext{
* Corresponding author, E-mail: shinichi.kawamura@tepco.co.jp

DOI : 10.15669/fukushimainsights.Vol.4.455

(C) 2021 Atomic Energy Society of Japan. All rights reserved.

Originally published in Transactions of the Atomic Energy Society of Japan (ISSN 1347-2879), Vol. 15, No. 2, p.53-65

(2016) in Japanese. (Japanese version accepted: November 6, 2015)
} 
the radiation outside the plant with the timing of the events that occurred in the plant, it is said that the Unit 2 reactor released the largest amount of radioactive material into the atmosphere of Units 1, 2 and 3, where core melting occurred. The Unit 2 reactor was the cause of the high level of contamination that occurred in the areas northwest of Fukushima Dai-ichi, particularly the village of Iitate ${ }^{1)}$.

In Unit 2, depressurization of the primary containment vessel (hereinafter referred to as "PCV") through venting failed. Although it is believed the leakage was a result of loss of the containment function of the PCV, the location and cause of the leakage have yet to be identified.

In addition, since PCVs are expected to maintain their containment function under conditions up to double the designed maximum working pressure and $200^{\circ} \mathrm{C}$, this is regarded as the precondition that must be taken into account by all domestic nuclear power stations when formulating severe accident measures. However, the maximum PCV pressure measured in Unit 2 was lower than this condition.

The new regulatory standards require nuclear power stations to install a PCV pressure relief system equipped with a radioactive material emissions reduction function called a filtered containment venting system (FCVS). However, for an FCVS to function effectively, a PCV needs to maintain its containment function. Otherwise, the radioactive materials have the potential to bypass the filter and be released. In addition, if the venting operation fails, as it did in Unit 2, it is possible that the containment function of the PCV may be lost before operating the vent.

Therefore, it is important to clarify the location and cause of the leaks from the PCV of Unit 2 when considering measures to operate the FCVS effectively and mitigate the consequences of an accident. In this article, we consider loss of the containment function in Unit 2 and discuss improvement measures based on our findings.

\section{Analysis of the Leakage from the PCV in Unit 2 of Fukushima Dai-ichi}

\section{Loss of the Containment Function of the PCV of Unit 2}

The actual measured pressure of the PCV of Unit 2, and the PCV pressure and temperature evaluated using MAAP code were published by the Tokyo Electric Power Company ${ }^{1)}$, as shown in Figure 1 and Figure 2.

The measured dry well pressure value of Unit 2 increased rapidly at around 22:40 on March 14 and then decreased significantly between 7:00 and 11:00 on March 15. The air dose rate near the main gate of Fukushima Dai-ichi increased rapidly from approximately $0.1 \mathrm{mSv} / \mathrm{h}$ to $10 \mathrm{mSv} / \mathrm{h}$ around the same time, but PCV venting was not conducted in Units 1 and 3 during that time. Therefore, it is believed that the PCV of Unit 2 lost its containment function around that time.

On the afternoon of March 14, the measured pressure values of the suppression chamber and dry well became significantly separated from each other and the measured pressure value of the suppression chamber decreased. Since both sections are connected via vent pipes, such separation does not occur as an actual phenomenon and is considered to be a result of a failure of the pressure indication of the suppression chamber.

The maximum pressure in the PCV measured before loss of the PCV function was approximately $0.75 \mathrm{MPa}$ [abs] and did not reach $0.95 \mathrm{MPa}$ [abs], the pressure limit for maintaining function (twice the maximum working pressure) assumed before the accident. In addition, the 


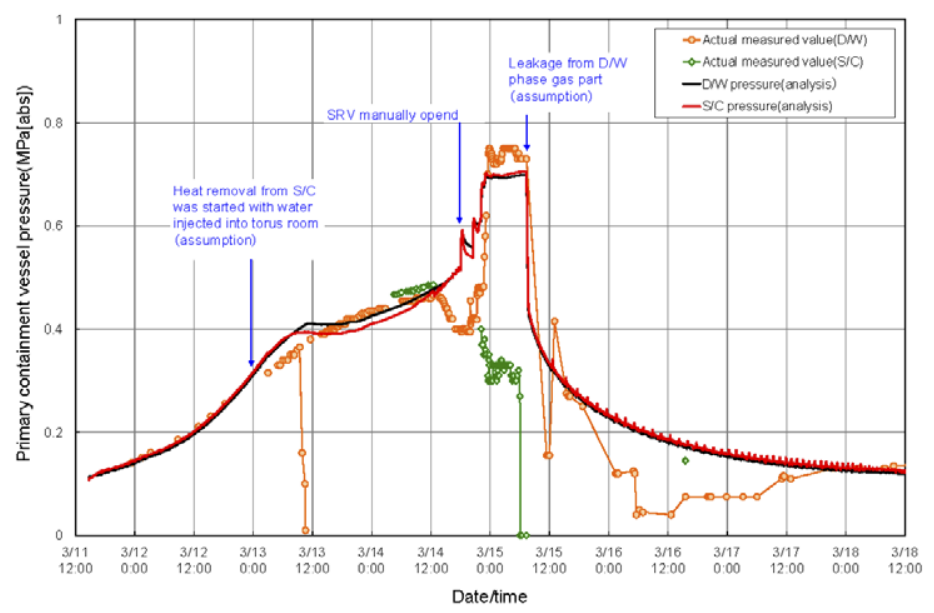

Figure 1 Pressure trend of the PCV at Fukushima Dai-ichi Unit $2^{1)}$

$\mathrm{D} / \mathrm{W}$ and S/C refer to the "dry well" and "suppression chamber" of the PCV respectively. SRV refers to the "safety relief valve."

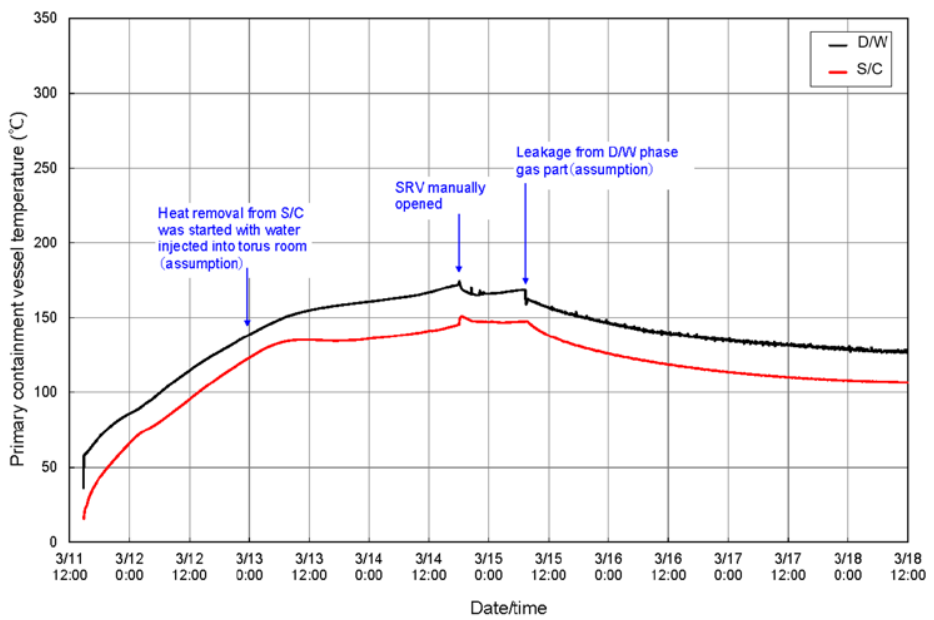

Figure 2 Temperature trend of the PCV at Fukushima Dai-ichi Unit 21) $\mathrm{D} / \mathrm{W}$ and S/C refer to the "dry well" and "suppression chamber" of the PCV respectively. SRV refers to the "safety relief valve."

maximum analytical value of the temperature in the PCV evaluated using MAAP code before loss of the containment function was approximately $175^{\circ} \mathrm{C}$ and did not reach $200^{\circ} \mathrm{C}$, the assumed temperature limit for maintaining function before the accident.

\section{Location of the Leakage that Caused Loss of the Containment Function of the PCV}

As mentioned above, loss of the containment function of the PCV of Unit 2 occurred between 7:00 and 11:00 on March 15. Figure 3 shows a photograph of Unit 2 taken on March 15. This photograph shows the steam discharged from the opening of a blow-out panel on the top 
floor of the reactor building. Figures 4-9 show the air radiation dose distributions measured in the Unit 2 reactor building after the accident. The dose rate distribution on the top floor of the reactor building (5th floor) is shown in Figure 4; the dose rate is high near the opening of the blow-out panel where the discharge of steam was observed, as shown in Figure 3. Therefore, it is estimated that a large amount of the radioactive material that leaked from the PCV due to loss of the containment function was released into the atmosphere from the opening of the blow-out panel.

In addition, according to the dose rate distribution on the 5th floor shown in Figure 4, the

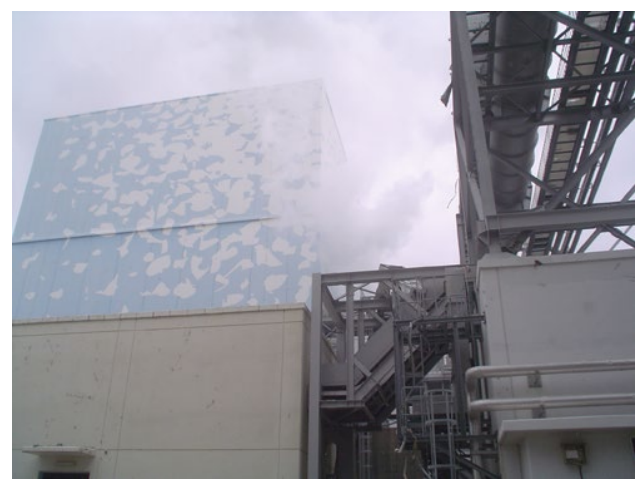

Figure 3 Steam coming out of a blow-out panel opening at the Fukushima Dai-ichi Unit 2 Reactor Building on March 15, 2011

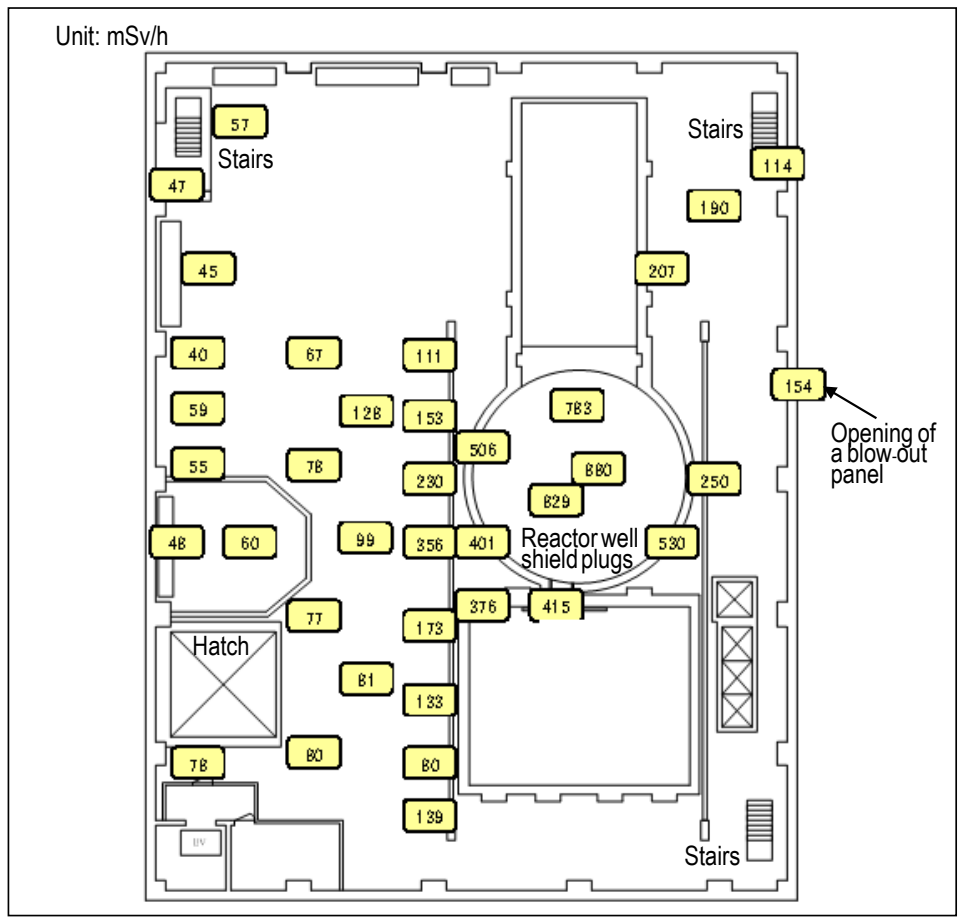

Figure 4 Spatial radiation dose rate on the 5th floor of the Fukushima Daiichi Unit 2 Reactor Building 


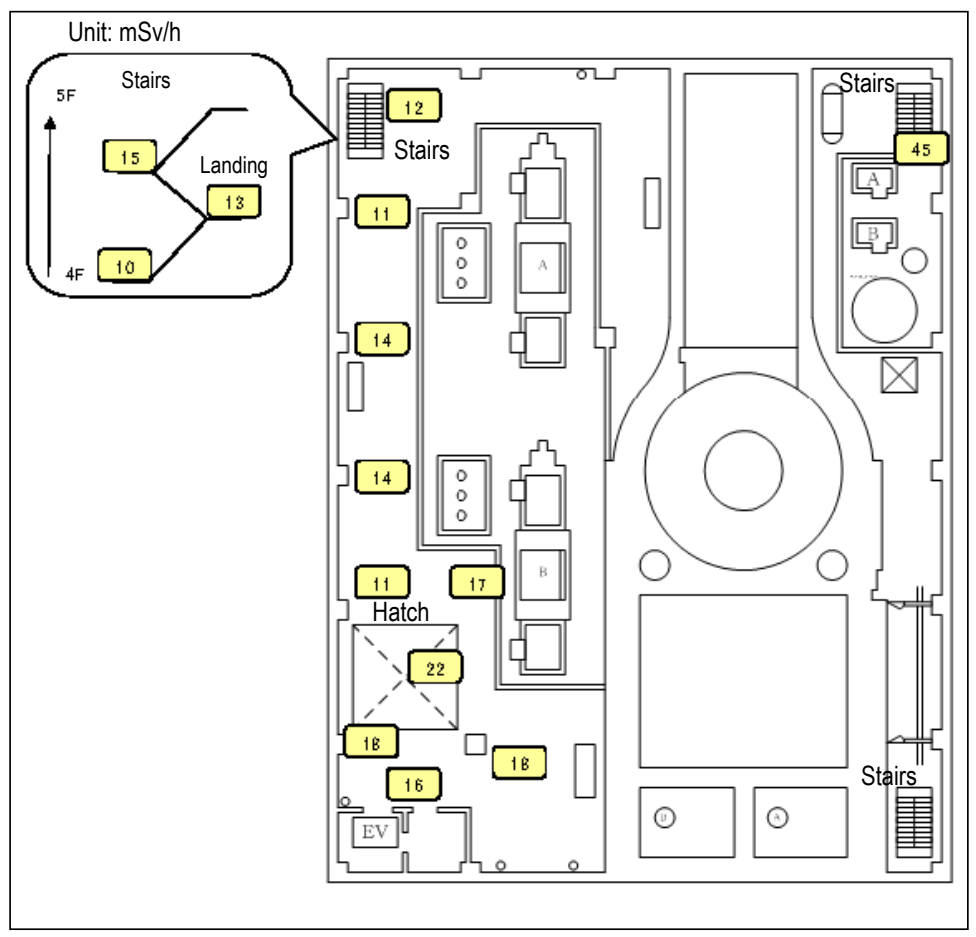

Figure 5 Spatial radiation dose rate on the 4th floor of the Fukushima Daiichi Unit 2 Reactor Building

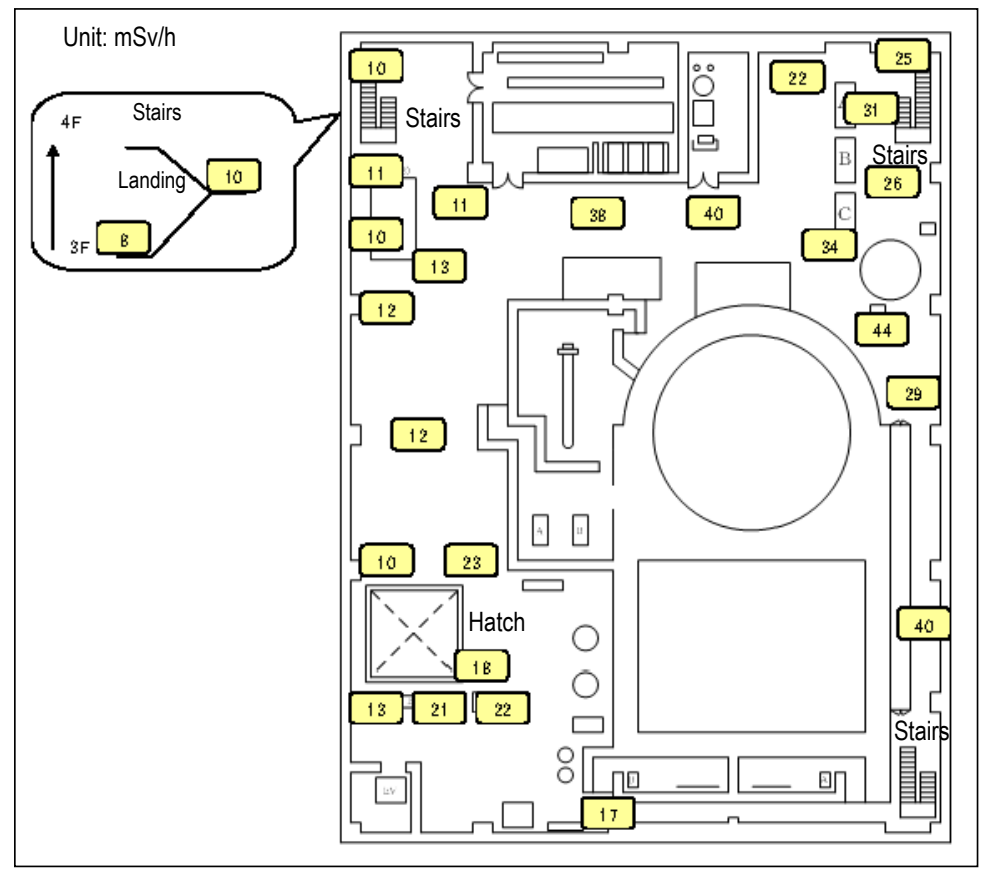

Figure 6 Spatial radiation dose rate on the 3rd floor of the Fukushima Daiichi Unit 2 Reactor Building 


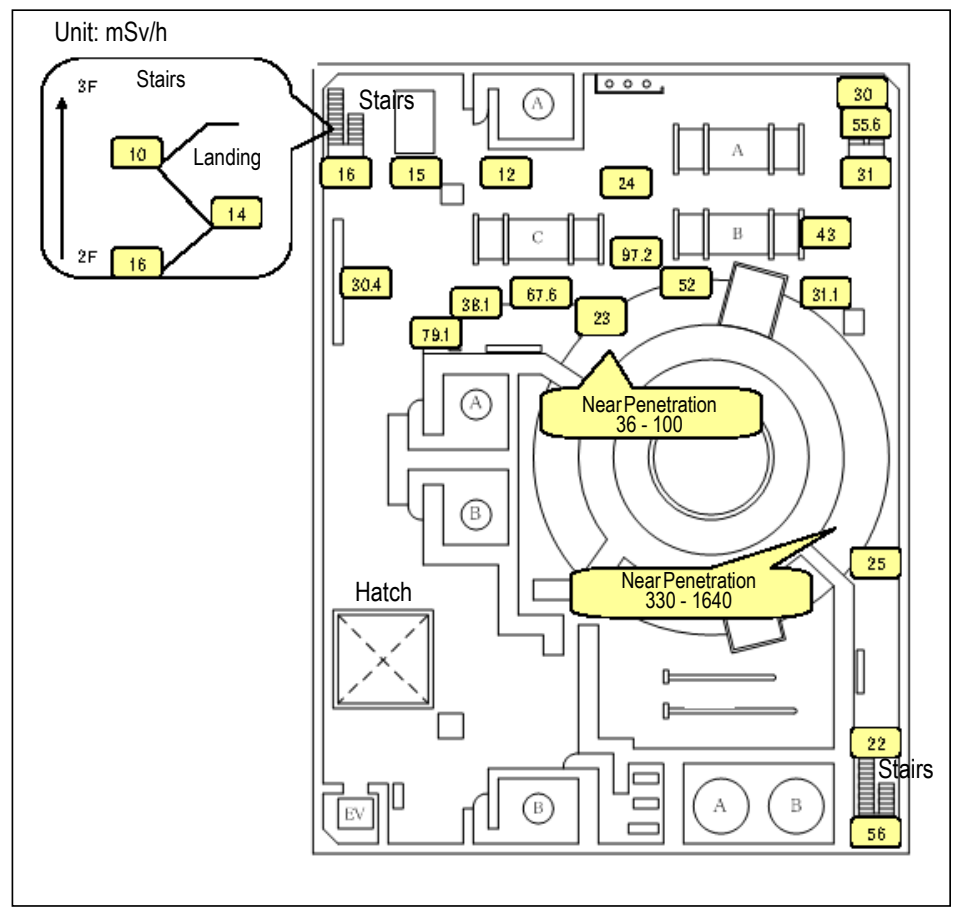

Figure 7 Spatial radiation dose rate on the 2nd floor of the Fukushima Dai-ichi Unit 2 Reactor Building

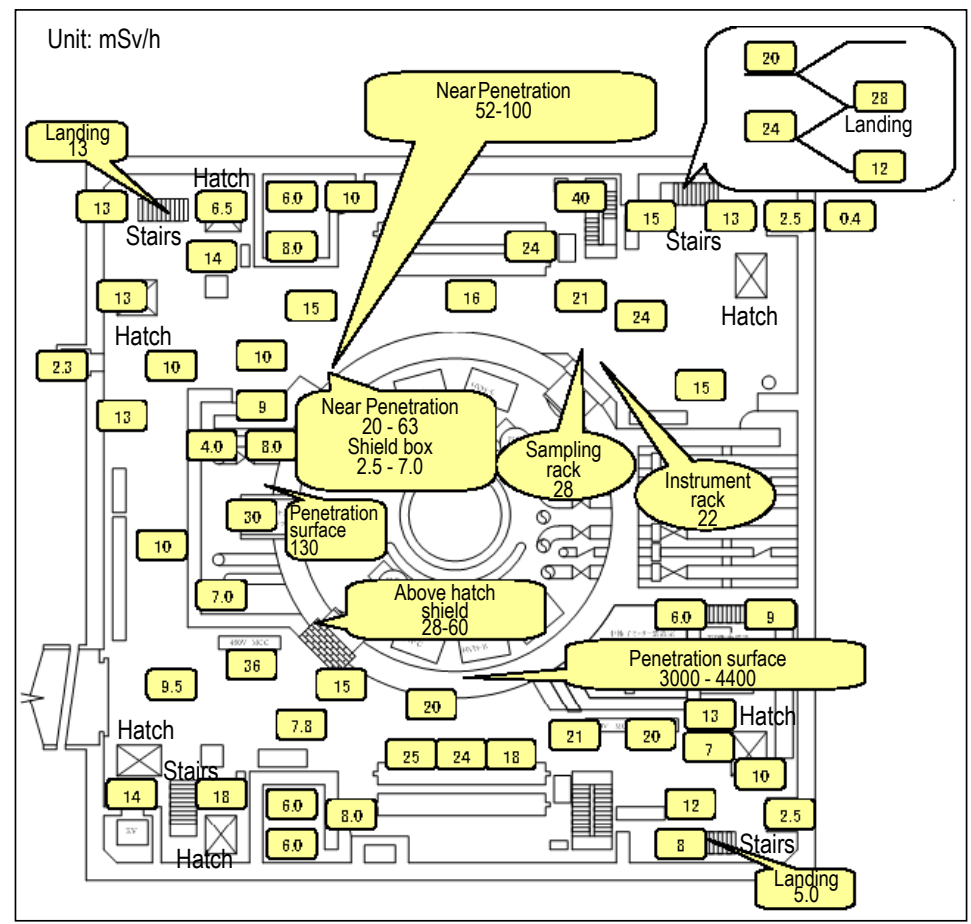

Figure 8 Spatial radiation dose rate on the 1st floor of the Fukushima Daiichi Unit 2 Reactor Building 


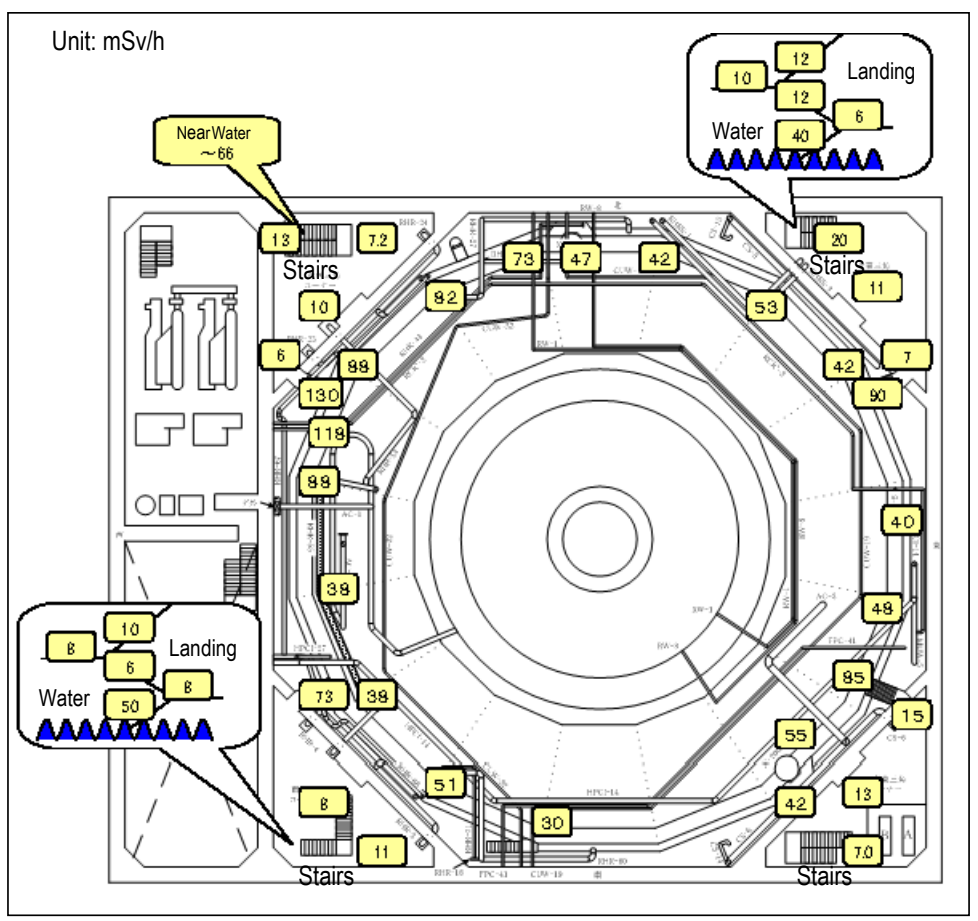

Figure 9 Spatial radiation dose rate in the middle basement of the Fukushima Dai-ichi Unit 2 reactor building

dose rates measured above the shield plug of the reactor well were higher than those measured in the surrounding area. On the other hand, the dose rates measured at the stairs connecting the 5th floor and the lower floor and near the hatch are lower than those measured above the shield plug. Furthermore, comparing the dose rates between the stairs on the 5th and 4th floors (Refer to Figure 5) and between the hatch on the 5th and 4th floor, they were higher on the 5th floor. Therefore, it seems unlikely that the leakage occurred on a lower floor and the radioactive materials reached the 5th floor through the stairs and the hatch opening and were then released into the atmosphere from the opening of the blow-out panel. Although the dose rate was not measured at the stairs shown on the lower right of the Figure, it is highly unlikely that the leakage occurred on a lower floor and the radioactive materials reached the 5th floor through the stairs because the stairs on the 4th and 3rd floors (Refer to Figure 6) passed between the shield wall of the spent fuel pool and the outer wall of the reactor building, creating no leakage path from the PCV. Additionally, the dose rate measured on the 2nd floor (Refer to Figure 7) was lower than that of the 5th floor. These investigation results suggest the possibility that a large amount of the radioactive material leaked from the PCV head flange directly beneath the shield plug of the reactor well.

Furthermore, Figures 8 and 9 show the dose rate distributions on the 1st floor and the middle basement, but the dose rates measured at the stairs and hatches were lower than those measured on the 5th floor, so it seems unlikely that they became advection paths for radioactive materials. Although high dose rates were measured near the PCV penetrations on these floors, the dose rates measured in the surrounding rooms and corridors were low. This is believed to be because of the influence of the radiation that transmitted from inside the PCV pressure boundary; however, significant leakage did not occur in these places. 
From the above, the leakage of radioactive materials into the atmosphere due to loss of the containment function of the PCV is considered to have occurred primarily from the top head of the PCV.

The water containing radioactive materials was retained in the triangular corner areas of the four corners of the reactor building shown in Figure 9. If a leakage occurred in the PCV or a system connected to the PCV such as the reactor core isolation cooling (RCIC) system in these areas, the containment function would have been lost, the PCV would depressurize, and the radioactive materials injected at high pressure would have spread high-concentration contamination to these triangular corner areas and stairs. However, the dose rates measured at those places were low, and the dose rates measured at the stairs increased with elevation. Therefore, the cause of the contamination of the retained water was distinct from the leakage that occurred when the containment function was lost - the contamination occurred after that.

The sealant for the top head flange of the PCV was made of silicone rubber. Silicone rubber is a material that can withstand relatively high temperatures because the binding energy of siloxane polymer, which is its basic structure, is greater than the carbon binding energy. However, in a high-temperature steam environment, siloxane polymer is hydrolyzed and disconnected; it is known that the performance of siloxane polymer decreases significantly at temperatures of $150^{\circ} \mathrm{C}$ or higher ${ }^{2}$. As Figure 2 shows, the dry well temperature exceeded $100^{\circ} \mathrm{C}$ on March 12 and was $150^{\circ} \mathrm{C}$ or higher on and after March 13. Therefore, it is believed that the deterioration of the silicone rubber occurred during that time. It withstood the increase in PCV pressure from 22:00 on March 14, but eventually lost its leakage resistance due to advanced deterioration.

\section{Venting Operation Problem}

It is possible that loss of the containment function of the PCV of Unit 2 could have been avoided if the pressure had been reduced by conducting containment venting before the top head flange sealant deteriorated or the PCV pressure increased rapidly in that state. However, this could not be achieved because the working venting pressure setting was high, and it was difficult to operate the venting valves.

Although Unit 2 was equipped with a hardened containment venting system as a measure to mitigate severe accidents, the set working pressure of the rupture disk incorporated into the venting system was $0.528 \mathrm{MPa}$ [abs] and was designed to allow venting at a higher pressure. This pressure was set according to the designed maximum working pressure of the PCV and was common to domestic plants before the accident occurred.

Instructions on venting preparation were issued by the head of the site emergency response organization (site superintendent) at 17:30 on March 12 when water injection into the reactor was continuously performed using the RCIC system. The site emergency response organization completed the operation for opening the valves required for venting by 11:00 on March 13 . However, as Figure 1 shows, the PCV pressure had not yet reached the set working pressure of the rupture disk at that moment, and the venting could not be started. Although the valves were kept open, it was confirmed on the site that the air-operated valve that had been kept open closed when the adjacent Unit 3 caused an explosion at 11:01 on March 14. After that, attempts were made to open the valve using a temporary air compressor, but the attempt to relieve the pressure in the PCV did not succeed, as shown in Figure 1.

Under these conditions, the PCV pressure increased rapidly at approximately 22:40 on March 14 and exceeded the set working pressure of the rupture disk for the first time.

This is believed to be because of a large amount of steam and hydrogen generated due to the water-zirconium reaction that occurred when seawater was injected by a fire engine. In 
Unit 2, water injection into the reactor was conducted using the RCIC system, but the loss of the reactor cooling function caused by the loss of the RCIC function was confirmed by the site emergency response organization at 13:25 on March 14. Because of this, the reactor water level decreased and reached the bottom of the active fuel around 18:10. It is believed that the water-zirconium reaction progressed rapidly because the fire engines were activated at 19:54 and 19:57 to inject seawater into the reactor ${ }^{1,3}$. The amount of hydrogen generated by this reaction, evaluated using the MAAP code, was approximately $460 \mathrm{~kg}$.

It could be also confirmed from the increase in the measurements of the containment atmospheric monitoring system (CAMS) that the core damage progressed after water injection into the reactor was resumed by a fire engine. Figure 10 shows the changes in the measurements of CAMS from 12:00 on March 14 to 0:00 on March 16. After water injection until around 0:00 on March 15, the measurements increased rapidly both in the dry well and the suppression chamber. This is believed to be a result of the rapid progress of the zirconium-water reaction due to water injection that caused the generation of a large amount of hydrogen and the release of fission products due to core damage. They were transferred to the suppression chamber via the main steam safety relief valves and to the dry well via the vacuum break valves. The reason why the indicated value of the suppression chamber is smaller than that of the dry well is because the CAMS on the suppression chamber side measure the dose rate outside the PCV.

Because the CAMS was unable to make measurements between 7:00 and 11:00 on March 15, when the PCV lost its containment function, the trend during that period is unknown. However, between 6:20 and 6:25, before measurement failure, the CAMS measurement of the dry well decreased rapidly from $62.7 \mathrm{~Sv} / \mathrm{h}$ to $43.0 \mathrm{~Sv} / \mathrm{h}$; it may have captured loss of the containment function in the dry well as well as the leakage into the reactor building, which is consistent with the above estimation that the containment function was lost due to leakage from the top head of the PCV. The CAMS measurement recorded its highest value at 16:10 on March 15, possibly due to the continuous progress of core damage that resulted in the relocation of the damaged core and breakage of the reactor.

As described above, it is considered that the containment function was lost due to leakage from the top head of the PCV because venting could not be conducted before a rapid increase in the PCV pressure due to the problem of the containment venting pressure setting and the operability of the valve required for venting, and because the sealant was deteriorated.

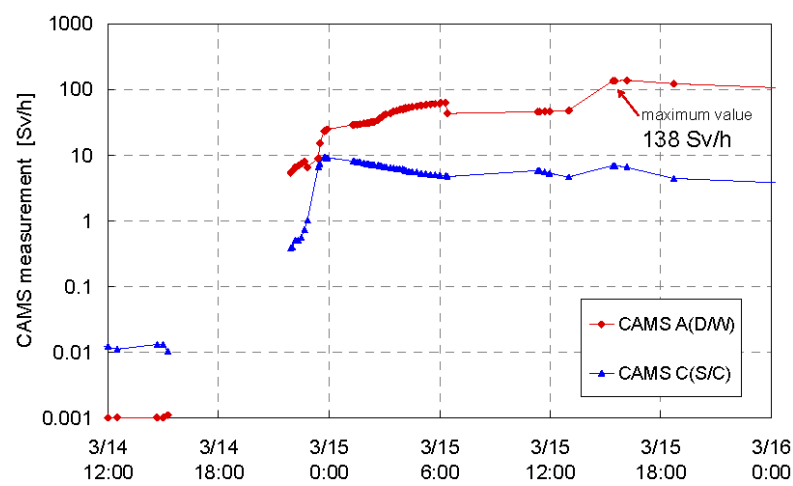

Figure 10 CAMS of the Fukushima Dai-ichi Unit 2 from March 14 to March 16, 2011

$\mathrm{D} / \mathrm{W}$ refers to the "dry well" and S/C refers to the "suppression chamber" of the PCV. 


\section{Mitigation of the Consequences after the PCV Lost its Containment Function}

Although the cause of loss of the containment function of the PCV of Unit 2 was discussed in previous sections, it is useful from the view point of resilience to consider whether the subsequent response was effective in mitigating the consequences at the time of the severe accident.

As Figure 11 shows, the CAMS measurement in Unit 2 decreased monotonically after it reached its peak at 16:10 on March 15. This indicates that continuous water injection cooled the fuel debris, which led to the suppression of the additional release of fission products.

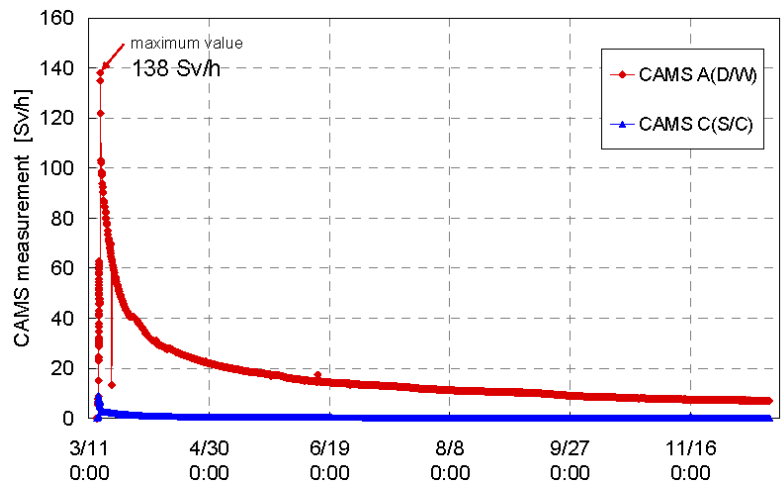

Figure 11 CAMS of the Fukushima Dai-ichi Unit 2 from March to November 2011

$\mathrm{D} / \mathrm{W}$ refers to the "dry well" and S/C refers to the "suppression chamber" of the PCV.

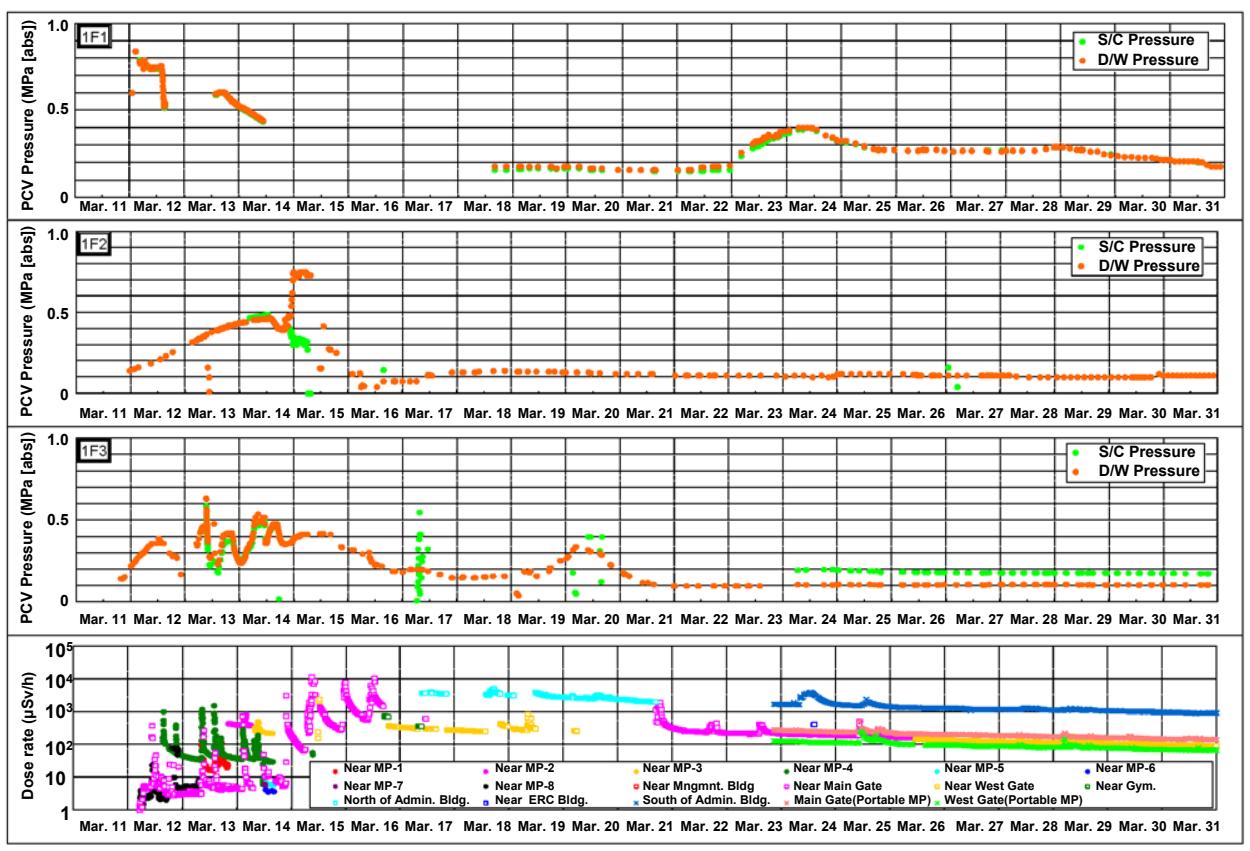

Figure 12 The PCV pressures of Units 1, 2 and $3(1 \mathrm{~F} 1,1 \mathrm{~F} 2$, and 1F3, respectively) as well as environmental radiation ${ }^{1)}$ 
The changes in the dose rate measured at the Fukushima Dai-ichi site and the changes in the PCV pressures of Units 1, 2 and 3 are as shown in Figure 12 ${ }^{1}$. It shows that continuous water injection reduced the dose rate almost monotonically on and after March 26 and the situation where a large amount of additional radioactive material could have been released into the atmosphere was avoided. In addition, the pressure in the PCV was stabilized through continuous water injection.

Therefore, continuing water injection to cool fuel debris and reduce the pressure in the PCV, even after it loses its containment function, is considered to be an effective mitigation measure.

\section{Improvement Based on the Lessons Learned from the Leakage from the PCV in Unit 2 of Fukushima Dai-ichi}

\section{Basic Policy for Improvement}

It was estimated above that the loss of the PCV's containment function in Unit 2 of Fukushima Dai-ichi occurred at the top head flange of the PCV and was caused by the deterioration of the gasket sealing material in a high-temperature steam environment and the increase in PCV pressure due to hydrogen and steam generated when water injection into the reactor was resumed. Thus, to maintain the radioactive material containment function of the PCV in a severe accident, it is important to systematically approach both temperature and pressure aspects in terms of the following:

- Mitigation of an increase in the PCV boundary temperature: Even in the situation where emergency systems have lost their function, using an alternative system, the increase in the PCV boundary temperature should be mitigated by spraying water in the PCV, injecting water immediately beneath the reactor to cool the fuel debris, and conducting water cooling of the outer surface of the top head of the PCV.

- Improvement of the heat resistance performance of the PCV boundary: Improve the sealant that constitutes part of the PCV boundary to enhance the leakage-resistance performance under a high-temperature steam environment.

- Prevention of a rapid increase in PCV pressure and an over-pressure exceeding the pressure limit: Enable the implementation of containment venting without fail before a rapid increase in pressure or an over-pressure occurs.

Of the above approaches, except for the cooling of the outer surface of the top head of the PCV by water injection, spray and water injection using an alternative system had been positioned as accident management measures before the accident at Fukushima Dai-ichi. Since the accident, further improvements, such as the addition of alternative power sources using gas turbine generators and the enhancement of the reliability in the operation of fire engines, have already been implemented.

The effectiveness of cooling a PCV using an alternative system in the event of a severe accident has been proven through an actual case. The increases in the temperature and pressure in the PCV were successfully mitigated to some extent in Units 1, 2 and 4 of the Fukushima Daini Nuclear Power Station by conducting alternative PCV spraying using make-up water condensate systems (MUWC) in the emergency situation after the Great East Japan Earthquake. In addition, enhancing the reliability of water injection in the event of a severe accident is important not only for maintaining the containment function of the PCV but also acts as a resilience measure in the event of PCV leakage, as discussed above. 
Since these measures have already been implemented, the following sections will examine methods for improving the sealant and the operation of containment venting - two important tasks to work on.

\section{Improvement of the Sealant}

\section{(1) Changing the sealing material}

For the purpose of maintaining leakage resistance performance under a high-temperature steam condition in the event of a severe accident, the material of the gasket used for the top head flange of the PCV was changed from conventional silicone rubber to improved ethylene-propylene-diene rubber (improved EPDM) ${ }^{4-6}$. The material possesses superior steam and radiation resistance and exhibited no deterioration-related behavior at the iodine concentration assumed to be present in a severe accident. Since the flange gasket of the hatches and the valve seals of the PCV were also made of silicone rubber, it was determined that improved EPDM should be utilized for these as well.

Furthermore, a backup sealing material (silicone-based one-component fire-resistant sealant) was added to the top head flange and the hatches ${ }^{4,7}$. This sealing material was applied to the flange surface located outside the gasket mounting groove. Although the leakage resistance performance was maintained by the gasket while a pressure higher than the maximum working pressure was applied to the PCV in a severe accident, the backup sealing material is intended to enhance the long-term maintenance of leakage resistance performance after the PCV pressure has been decreased through containment venting, etc. Even if the flange remains at high temperatures for a long time after the accident, the backup sealing material can maintain its leakage resistance performance independently and is also expected to reduce oxidation degradation of the improved EPDM gasket by blocking external air.

Figure 13 presents a diagram of the conceptual layout of the sealants in the top head flange of the PCV. They are arranged in the same way in the hatch flanges.

\section{(2) Environmental qualification test for the sealants made of improved EPDM}

We conducted a test to determine if the improved EPDM sealants could maintain their performance in the environment created by a severe accident.

In this test, a sealing material exposed to $\gamma$-ray irradiation of $800 \mathrm{kGy}$ was mounted on a simulated flange, exposed to a dry air environment at $200^{\circ} \mathrm{C}$ or a steam environment at $250^{\circ} \mathrm{C}$ for 168 hours, and then pressurized up to $0.9 \mathrm{MPa}$ [gage] with helium to check if airtightness was maintained. The irradiation dose was determined considering the accumulated radiation dose for seven days after the accident caused by the combined event of loss of coolant (large-break LOCA), station blackout, and a total loss of emergency core cooling system functions - a typical severe accident sequence which leads to over-pressure and over-temperature of the PCV in a boiling water reactor (BWR) plant. In addition, the high-temperature exposure condition was set

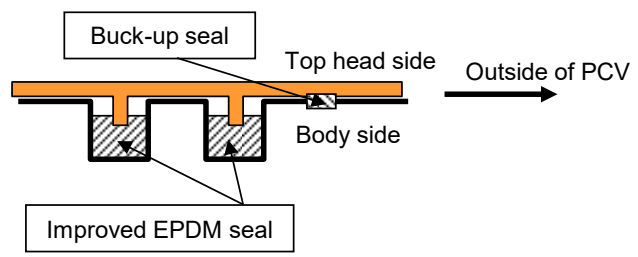

Figure 13 Seal arrangement of the PCV top head flange 
to exceed $200^{\circ} \mathrm{C}$, which was the limit temperature for the PCV leading to containment venting.

In addition to the steam environment to which the sealants are exposed in the event of an accident, they were also exposed to high temperatures generated by dry air which have the potential to lead to deterioration through an oxidation reaction.

Figure 14 shows the external appearance of the simulated flange used for the test. The seal groove of the simulated flange and the section size of the mounted sealing material were half those of the actual system. In addition, a step was provided inside the simulated flange to simulate a situation where the PCV is pressurized and the flange is opened in the event of an accident, and the sealing material was exposed to high-temperature steam while mounted on the flange. After it was exposed to a predetermined environment in the autoclave, it was pressurized by helium to check its airtightness .

In the event of an accident, the sealing material is exposed to radiation while it is mounted on the flange. In this test, post-radiation sealing material was mounted on the flange and controlled so that face-to-face dimension at the sealing material mounting groove could simulate the actual system when the flange was tightened. In this way, it is possible to determine the airtightness of the actual system because the tightening condition could be controlled without being influenced by a change in the physical properties of the sealing material due to irradiation.

In addition, in the case of domestic BWR plants where the PCV is filled with nitrogen gas, the PCV is pressurized with a gas mixture consisting mainly of nitrogen, hydrogen, and water vapor in the event of a severe accident. In this test, we used helium, which has a lower molecular weight than the average molecular weight of this mixture gas and a small molecular radius in terms of hydrogen simulation. This enabled us to easily maintain safety during the experiment. The technical standard for automobile fuel systems fueled by compressed hydrogen gas (Notice Defining the Details of the Safety Standards for Road Transport Vehicles (Attachment 100) ${ }^{8)}$ requires that the helium leak rate should be multiplied by 1.33 to estimate the hydrogen leak rate. On the other hand, the helium leak rate is multiplied by 1.41 to correct the leak rate by raising the gas constant ratio to the 0.5 th power according to the guides stipulated by U.S. Atomic Energy Commission governing the evaluation of the leak rate of PCVs ${ }^{9}$. In this test, by using an extremely low leak rate condition with no pressure decrease during airtightness testing and no bubble generation with bubble solution as the judgment criterion, we found that adaptability to the actual system could be determined using helium gas without any problems.

Table 1 shows the results of the airtightness test. After pressurized to $0.3 \mathrm{MPa}$ [gage], the test system was retained for ten minutes. Then, it was pressurized again and retained for thirty minutes after reaching at $0.65 \mathrm{MPa}$ [gage] and at $0.9 \mathrm{MPa}$ [gage]. During each retention period, no pressure drop was observed. In addition, no bubble generation was observed in the leakage check using bubble solution and superior airtightness was confirmed. Furthermore, we also conducted a helium airtightness test in the same way with the flange test piece after opening

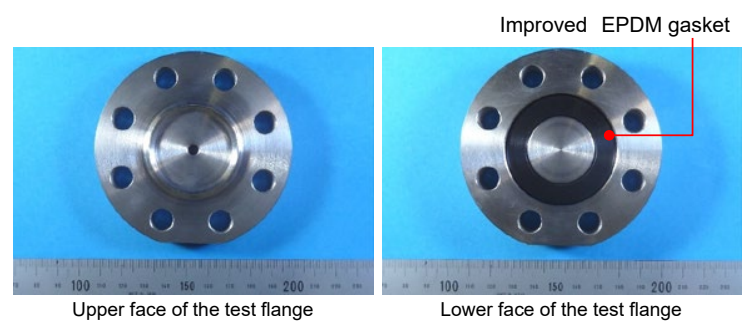

Figure 14 Test flange and improved EPDM gasket 
Table 1 Air tightness test of the improved EPDM gasket using helium after radiation exposure of $800 \mathrm{kGy}$ and thermal exposure

\begin{tabular}{ccccc}
\hline $\begin{array}{c}\text { Thermal } \\
\text { exposure }\end{array}$ & $\begin{array}{c}\text { Flange } \\
\text { opening }\end{array}$ & \multicolumn{3}{c}{ Test pressure } \\
$0.3 \mathrm{MPa}$ & $0.65 \mathrm{MPa}$ & $0.9 \mathrm{MPa}$ \\
\hline $\begin{array}{c}\text { Dry air } 200^{\circ} \mathrm{C} \\
168 \text { hours }\end{array}$ & $0.8 \mathrm{~mm}$ & $\begin{array}{c}\text { No } \\
\text { leakage }\end{array}$ & $\begin{array}{c}\text { No } \\
\text { leakage }\end{array}$ & $\begin{array}{c}\text { No } \\
\text { leakage }\end{array}$ \\
\hline $\begin{array}{c}\text { Steam } 250^{\circ} \mathrm{C} \\
168 \text { hours }\end{array}$ & $0.8 \mathrm{~mm}$ & $\begin{array}{c}\text { No } \\
\text { leakage }\end{array}$ & $\begin{array}{c}\text { No } \\
\text { leakage }\end{array}$ & $\begin{array}{c}\text { No } \\
\text { leakage }\end{array}$ \\
\hline
\end{tabular}

it by $0.8 \mathrm{~mm}$ using a jig after exposure to high temperature, considering that the flange opens when it is pressurized in the event of an accident. Since the section sizes of the simulated flange and gasket used in this test are half of those used in an actual system, an opening of $0.8 \mathrm{~mm}$ in the test system corresponded to the $1.6 \mathrm{~mm}$ opening in an actual system. In the case of a PCV in an advanced BWR (ABWR) plant, the flange of the equipment hatch has the largest opening displacement when the pressure doubles the maximum working pressure in the event of an accident. Although the displacement becomes larger on the inner gasket side than on the outer gasket side, it was approximately $1.4 \mathrm{~mm}$ on the inner gasket side, which is within the range of the opening condition set in this test. No leakage was observed in this test and it was confirmed that airtightness was maintained through the resiliency of the sealing material (which was compressed in advance and installed) even if an opening was created when the PCV was pressurized at a pressure double the maximum working pressure.

In addition, as a result of checking the external appearance of the sealing material after the test, no abnormalities such as cracks were observed on the surface.

In the case of a severe accident in an actual plant, measures are taken to decrease the temperature and pressure of the PCV by conducting containment venting or alternative recirculation cooling within a few days following the accident (less than a week). From the above test result, it is evident that the sealing material made of improved EPDM can maintain its leakage resistance performance under a severe accident environment, at least until then.

\section{(3) The environmental qualification test of the backup sealing material}

We also conducted environmental qualification test of the backup sealing material. In this test, the simulated flange to which the backup sealing material was applied was irradiated with $\gamma$-rays of $800 \mathrm{kGy}$ or higher to simulate the accumulated radiation dose seven days after an accident, and it was exposed to a steam environment of $250^{\circ} \mathrm{C}$ for 168 hours. Then, it was pressurized up to $0.9 \mathrm{MPa}$ with helium to check airtightness. Figure 15 shows the condition of the airtightness test and Table 2 shows the test results. In an actual system, the backup sealing material is used in combination with a gasket made of improved EPDM. However, in this test, only the sealing material was applied, and the gasket was not mounted to confirm the performance. The retention times for each pressure in the airtightness test were ten minutes at $0.3 \mathrm{MPa}$ and thirty minutes at $0.65 \mathrm{MPa}$ and $0.9 \mathrm{MPa}$. During each retention period, no bubble generation was observed in the leakage check using bubble solution and no pressure drop was observed. And the results demonstrated superior airtightness.

Next, in terms of maintaining the leakage resistance performance for long periods following an accident, we conducted long-term, high-temperature exposure at a temperature of $200^{\circ} \mathrm{C}$ with a combination of a gasket made of improved EPDM (irradiated with $\gamma$-rays of $800 \mathrm{kGy}$ ) and backup sealing material. After exposure, the test system was pressurized with helium and retained for ten minutes at $0.3 \mathrm{MPa}$ and thirty minutes at $0.65 \mathrm{MPa}$ and $0.9 \mathrm{MPa}$ to confirm the airtightness performance. Table 3 shows the test results. Under these conditions, no bubble 


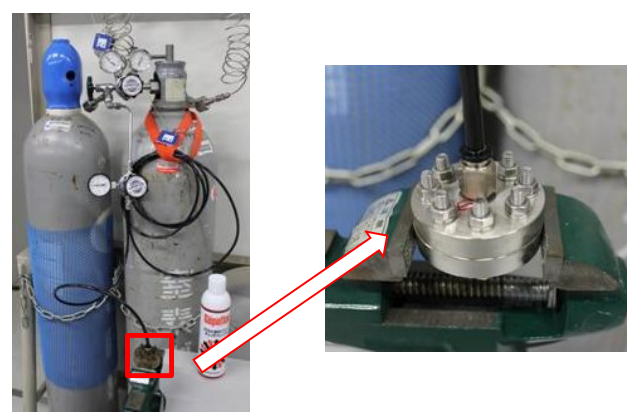

Figure 15 Air tightness test of back-up seal using helium

Table 2 Air tightness test of back-up seal using helium after radiation exposure of $819 \mathrm{kGy}$ and thermal exposure

\begin{tabular}{ccccc}
\hline $\begin{array}{c}\text { Thermal } \\
\text { exposure }\end{array}$ & $\begin{array}{c}\text { Flange } \\
\text { opening }\end{array}$ & \multicolumn{3}{c}{ Test pressure } \\
$0.3 \mathrm{MPa}$ & $0.65 \mathrm{MPa}$ & $0.9 \mathrm{MPa}$ \\
\hline $\begin{array}{c}\text { Steam } 250^{\circ} \mathrm{C} \\
168 \text { hours }\end{array}$ & $0 \mathrm{~mm}$ & $\begin{array}{c}\text { No } \\
\text { leakage }\end{array}$ & $\begin{array}{c}\text { No } \\
\text { leakage }\end{array}$ & $\begin{array}{c}\text { No } \\
\text { leakage }\end{array}$ \\
\hline
\end{tabular}

Table 3 Air tightness test of the improved EPDM gaskets and back-up seals using helium after extended periods of thermal exposure

\begin{tabular}{ccccc}
\hline $\begin{array}{c}\text { Thermal } \\
\text { exposure }\end{array}$ & $\begin{array}{c}\text { Flange } \\
\text { opening }\end{array}$ & \multicolumn{3}{c}{ Test pressure } \\
\hline $\begin{array}{c}\text { Dry air } 200^{\circ} \mathrm{C} \\
720 \text { hours }\end{array}$ & $0 \mathrm{~mm}$ & $\begin{array}{c}\text { No } \\
\text { leakage }\end{array}$ & $\begin{array}{c}\text { No } \\
\text { leakage }\end{array}$ & $\begin{array}{c}\text { No } \\
\text { leakage }\end{array}$ \\
\hline $\begin{array}{c}\text { Dry air } 200^{\circ} \mathrm{C} \\
1,080 \text { hours }\end{array}$ & $0 \mathrm{~mm}$ & $\begin{array}{c}\text { No } \\
\text { leakage }\end{array}$ & $\begin{array}{c}\text { No } \\
\text { leakage }\end{array}$ & $\begin{array}{c}\text { No } \\
\text { leakage }\end{array}$ \\
\hline $\begin{array}{c}\text { Dry air } 200^{\circ} \mathrm{C} \\
1,440 \text { hours }\end{array}$ & $0 \mathrm{~mm}$ & $\begin{array}{c}\text { No } \\
\text { leakage }\end{array}$ & $\begin{array}{c}\text { No } \\
\text { leakage }\end{array}$ & $\begin{array}{c}\text { No } \\
\text { leakage }\end{array}$ \\
\hline $\begin{array}{c}\text { Dry air } 200^{\circ} \mathrm{C} \\
1,800 \text { hours }\end{array}$ & $0 \mathrm{~mm}$ & $\begin{array}{c}\text { No } \\
\text { leakage }\end{array}$ & $\begin{array}{c}\text { No } \\
\text { leakage }\end{array}$ & $\begin{array}{c}\text { No } \\
\text { leakage }\end{array}$ \\
\hline $\begin{array}{c}\text { Dry air } 200^{\circ} \mathrm{C} \\
2,160 \text { hours }\end{array}$ & $0 \mathrm{~mm}$ & $\begin{array}{c}\text { No } \\
\text { leakage }\end{array}$ & $\begin{array}{c}\text { No } \\
\text { leakage }\end{array}$ & $\begin{array}{c}\text { No } \\
\text { leakage }\end{array}$ \\
\hline $\begin{array}{c}\text { Dry air } 200^{\circ} \mathrm{C} \\
2,520 \text { hours }\end{array}$ & $0 \mathrm{~mm}$ & $\begin{array}{c}\text { No } \\
\text { leakage }\end{array}$ & $\begin{array}{c}\text { No } \\
\text { leakage }\end{array}$ & $\begin{array}{c}\text { No } \\
\text { leakage }\end{array}$ \\
\hline
\end{tabular}

generation or pressure drop was observed in the leakage confirmation conducted using bubble solution, and superior airtightness was demonstrated. This test confirmed that the leakage resistance performance can be expected to be maintained for long periods after an accident.

\section{Improvement of the Containment Venting Operation}

The above analysis result concerning loss of the containment function of the PCV in Unit 2 suggests that it is desirable to decrease the PCV pressure by conducting venting in advance, as the PCV pressure increases rapidly when water injection into the reactor is resumed with the fuel exposed ${ }^{10}$. In addition, if the venting system is kept in service even after the pressure decrease, the influence of the generation of a large amount of non-condensable gas can be mitigated. Such operations should be considered in the future because radioactive material 
emissions due to venting can be reduced with the FCVS installed.

In the past, the containment venting conditions have been discussed in terms of the relationship with the maximum working pressure of the PCV or pressure twice the maximum working pressure and have also been reflected in the operation procedures to be followed in the event of an accident. As a result, the working pressure of the rupture disk incorporated into the venting system was set according to the maximum working pressure of the PCV. However, it is necessary to not only check whether the preset pressure is reached but to also operate containment venting flexibly to put the containment venting system into service in advance-irrespective of the pressure at the time - if a rapid increase in the PCV pressure is predicted as was the case for Unit 2 of Fukushima Dai-ichi. In addition, venting has the effect of decreasing the saturation temperature of steam through depressurization to cool the PCV and discharging hydrogen to prevent the accumulation of combustible gas. Thus, venting should be conducted in accordance with the situation. For this purpose, the rupture disk should either not be installed or should be configured to operate at low pressures if it is installed.

Furthermore, in the operation procedures to be followed in the event of a severe accident, attention must be paid to the generation of a large amount of non-condensable gas or steam when water injection into the reactor is resumed after being suspended.

In addition, in Unit 2, the pressure inside the PCV could not be relieved before loss of the containment function of the PCV because one of the valves of the containment venting system could not be kept in the open position and the operation for opening the closed valve failed. Since the valve was air-operated and the solenoid valve which controlled the air was designed to be operated remotely from the main control room, there was no on-site feature for opening and closing the valves. Therefore, in addition to remote operation from the main control room, a feature that enables the on-site, hand operation of the valves for containment venting should be provided so that venting can be conducted at any time. Figure $\mathbf{1 6}$ shows an example in which the valve operating mechanism was extended to outside the secondary containment, where the radiation level is low even in the event of an accident so that the valve can be operated

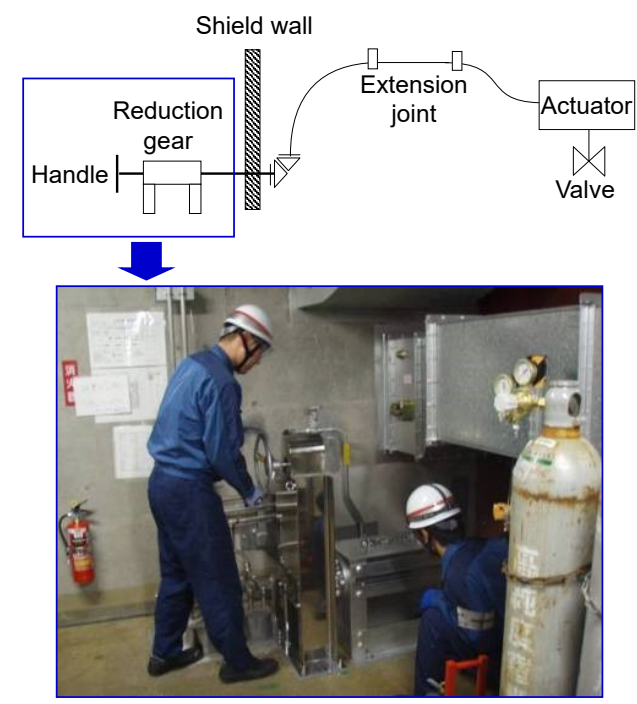

Figure 16 Example of a manual operation device for a valve in the filtered containment venting system installed outside the secondary containment boundary 
manually and kept open. This feature can be incorporated into both motor-operated valves and air-operated valves that have a ratchet mechanism in their drive mechanisms.

\section{Conclusions}

In the accident that occurred at Fukushima Dai-ichi, Unit 2 was responsible for releasing the largest amount of radioactive material into the atmosphere, which is said to be the cause of the high level of contamination found in areas northwest of Fukushima Dai-ichi, particularly the village of Iitate. In Unit 2, a significant decrease in the PCV pressure was observed on the morning of March 15 before the pressure limit was reached, at which point it was thought that containment function of the PCV was still maintained. However, it is now believed that the containment function was lost at that point in time, but details of location and cause of leakage have not been examined.

Based on the situation of the contamination in the Unit 2 reactor building and the temperature and pressure trends in the PCV at the time of the accident, we estimate that it is highly possible that this leakage occurred at the top head flange of the PCV due to the deterioration of the silicone rubber used for the flange gasket under a high-temperature steam environment.

Based on the lessons learned from this accident, it is necessary to promote the following three systematic approaches related to temperature and pressure to maintain the containment performance of the PCV in the event of a severe accident: the mitigation of an increase in the PCV boundary temperature through alternative spray and water injection; the enhancement of the heat resistance of the PCV boundary through improvement of the sealants; and the effective venting of the PCV before a rapid pressure increase or an over-pressure.

Among these approaches, this study confirmed through a test that leakage resistance performance in a high-temperature steam environment in the event of a severe accident was enhanced by using improved EPDM as the sealing material instead of conventionally used silicone rubber. In addition, we also devised a new way of applying backup sealing materials to the flange using fire-resistant sealant, which was shown to be effective in securing the reliability of leakage resistance for long periods of time after the accident. These measures are expected to enhance the heat resistance performance of the PCV boundary.

Furthermore, concerning the operation of containment venting, in addition to the traditional approach that venting is conducted depending on whether the PCV has reached a preset pressure, it was found to be beneficial to put the venting system into service in advance if there is any possibility that the PCV pressure may increase rapidly due to the generation of large amounts of non-condensable gas and steam; for example, in a case where water injection into the reactor is resumed after it was suspended. Through the operation of venting in a situation like this, the possibility of PCV failure should be reduced as much as possible. In addition, because venting is also effective in decreasing the PCV temperature and preventing an accumulation of flammable gas, it is also important to operate venting according to the situation. Such flexible operation of the containment venting should be incorporated into accident operation procedures and the improved operation mechanism should be applied to the valves in the venting system to enable such operation.

\section{References}

1) Tokyo Electric Power Company, Fukushima Nuclear Accident Analysis Report, http://www.tepco.co.jp/ en/press/corp-com/release/2012/1205638_1870.html as of November 2015, (2012). 
2) S. Takenobu, "Kakusyu gomu compound no tainetsu taisui jouki siken kekka," Valqua Rev., 21[3], 8-14 (1977). [in Japanese]

3) M. Ishikawa, Koushou Fukushima Genshiryoku Jiko, Denkikyokai Shimbunbu, Tokyo, ISBN978-4905217-34-3 C0036 (2014). [in Japanese]

4) S. Kawamura, S. Omori, T. Kimura, T. Takiguchi, T. Narabayashi, "A comprehensive approach to reducing radioactive material release in BWR containment venting," Proc. 20th Nat. Symp. on Power and Energy Systems, Sendai, Japan, Jun. 18-19, 2015 (2015). [in Japanese]

5) Y. Furuhashi, S. Ooki, Y. Ibusuki, R. Shimosakoda, A. Taniguchi, T. Kimura, N. Hiranuma, S. Murai, H. Tezuka, "Applicability evaluation of EPDM rubber sheet for butterfly valve of primary containment vessel (2) Fundamental behavior of EPDM rubber sheet under steam with iodine and its iodine durability under simulated severe accident condition," Proc. 2015 Fall Meeting of Atomic Energy Society of Japan, Shizuoka, Japan, Sep. 9-11, 2015 (2015). [in Japanese]

6) S. Ooki, Y. Ibusuki, R. Shimosakoda, A. Taniguchi, "Improvement of sealing performance at flanges and hatches in primary containment vessels," Proc. 2015 Annu. Conf. on Power and Energy Society IEE Japan, Nagoya, Japan, Aug. 25-27, 2015 (2015). [in Japanese]

7) S. Ooki, Y. Ibusuki, R. Shimosakoda, N. Hayashi, H. Abe, A. Taniguchi, "Studies on back up seal material to flanges and hatches on primary containment vessels," Proc. 2015 Annu. Conf. of Fundamentals and Materials Society IEE Japan, Kanazawa, Japan, Sep. 17-18, 2015 (2015). [in Japanese]

8) Ministry of land, infrastructure, transport and tourism, Notice Defining the Details of the Safety Standards for Road Transport Vehicles (Attachment 100), (2005). [in Japanese]

9) U. S. Atomic Energy Commission, Reactor Containment Leakage Testing and Surveillance Requirements, Safety standards, criteria, and guides for the design, location, construction, and operation of reactors, III. Technical safety guide (1966).

10) T. Narabayashi, S. Kawamura, "Development of high efficiency filtered containment venting system by using AgX," Proc. 20th Nat. Symp. on Power and Energy Systems, Sendai, Japan, Jun. 18-19, 2015(2015). [in Japanese] 